\title{
O ensino religioso nas políticas de currículo: o caso da base nacional comum curricular
}

\author{
Educación religiosa de las políticas del currículo: \\ el caso de la base del currículo de la base del currículo común nacional
}

\author{
The religious education policy curriculum: \\ the case of the national curriculum commom core
}

Mirinalda Alves Rodrigues dos Santos'

Palavras chave:

Ensino religioso

Políticas de currículo

Base Nacional Comum Curricular
Resumo:

Este artigo é fruto das reflexões e discussões acerca dos estudos curriculares e do campo da(s) Ciência(s) da(s) Religião(ões) frente ao Ensino Religioso - ER, bem como o seu reconhecimento como componente curricular na Base Nacional Comum Curricular - BNCC, cuja política de currículo será referência no que diz respeito aos conteúdos e saberes necessários para traçar os objetivos de aprendizagens a serem ensinados e apreendidos pelos educandos nas escolas públicas e particulares do Brasil. Entretanto, na terceira versão da BNCC aprovada pelo Ministério da Educação - MEC o Ensino Religioso foi retirado desse documento, até o presente momento, esse ensino estava presente nas duas últimas versões da BNCC.E, recentemente, o Ensino Religioso volta a ser reconhecido como componente curricular no referido documento. É nesse sentido que o objetivo desse trabalho é analisar os discursos produzidos nas Políticas Públicas de Currículo, acerca da exclusão/ inclusão do Ensino Religioso na BNCC. Metodologicamente esse estudo é de cunho bibliográfico e documental com delineamento explicativo, reflexivo e crítico. Diante das análises realizadas nesse estudo frente ao Ensino Religioso na BNCC podemos concluir, portanto, que o documento proposto é mais um artefato para legitimar hegemonias, preconceitos, discriminações, e relações de poder no que se tratam as questões religiosas, diante da representatividade conservadora no atual cenário político que estamos vivenciando. 


\section{Resumen:}

Este artículo es el resultado de reflexiones y discusiones acerca de los estudios plan de estudios y campo de la ciencia de la parte delantera de la religión (s) de Educación Religiosa-ER, así como su reconocimiento como componente curricular en Base de Currículo Común Nacional.- BNCC, cuyo plan de estudios hará referencia política en relación con el contenido y el conocimiento necesario para trazar los objetivos de aprendizaje para ser enseñado y aprendido por los estudiantes en escuelas públicas y privadas de Brasil. Sin embargo, en la tercera versión del BNCC aprobado por el Ministerio de educación-MEC que la instrucción religiosa fue quitada de este documento, tenía hasta entonces esta enseñanza en las dos últimas versiones en BNCC. Y, recientemente, la Enseñanza de la religión vuelve a ser reconocido como un componente curricular en dicho documento. Es en este sentido que el objetivo de este trabajo es analizar los discursos producidos en las Políticas Públicas de plan de estudios, acerca de la exclusión/inclusión de la Enseñanza de la religión en la BNCC. Metodológicamente, este estudio es de tipo bibliográfico y documental con el estudio explicativo, reflexivo y crítico. En el análisis realizados en este estudio frente a la Enseñanza de la religión en la BNCC podemos concluir, por tanto, que el documento propuesto es más un artefacto para legitimar hegemonías, los prejuicios, la discriminación y las relaciones de poder en el que se tratan las cuestiones religiosas, ante la representatividad conservadora en el actual escenario político que estamos viviendo.

\section{Palabras clave:}

Educación religiosa

Políticas del Currículo

Base de Currículo

Común Nacional

\section{Keywords:}

Religious Education

Curriculum Policy

National Curriculum Common Core

\section{Abstract:}

This article is the result of the reflections and discussions about curricular studies and the field of Science (s) of Religion (s) in relation to Religious Education - RE, as well as its recognition as a curricular component in the National Common Curricular Base -BNCC,whose curriculum policy will be a reference in terms of contents and knowledge needed to trace learning objectives to be taught and perceived by students in public and private schools in Brazil. However, in the third version of the NCCB approved by the Ministry of Education - MEC the Religious Education was removed from this document, until this moment, this teaching was present in the last two versions of the BNCC. And, recently, Religious Education is once again recognized as a curricular component in this document. It is in this sense that the objective of this work is to analyze the discourses produced in the Curriculum Public Policies, about the exclusion / inclusion of Religious Education in the BNCC. Methodologically, this study is a bibliographic and documentary character with explanatory, reflexive and critical delineation. Methodologically, this study is of a bibliographic and documentary character with explanatory, reflexive and critical design. In view of the analyzes carried out in this study regarding Religious Education at the BNCC, we can conclude that the proposed document is more an artifact to legitimize hegemonies, prejudices, discriminations, and power relations in what concerns religious issues, given the conservative current political scenario we are experiencing. 


\section{0 ensino religioso nas políticas de currículo: o caso da base nacional curricular}

\section{Introdução}

No campo das políticas educacionais muito se tem discutido acerca da implementação da Base Nacional Comum Curricular - BNCC no ano de 2014, como uma Política de Currículo a ser seguida com estratégias de conteúdos e competências no processo de ensino-aprendizagem na educação básica. Essa perspectiva de currículo desde a sua primeira versão até a sua terceira versão é alvo de muitas críticas em todos os componentes curriculares, inclusive no Ensino Religioso, que por sua vez era presente nas duas versões anteriores e foi retirada na terceira versão da BNCC e, recentemente sendo incluído novamente na Base.

Antes dessa exclusão, o Ensino Religioso na BNCC quando foi reconhecido nesse documento foi alvo de críticas, por propor diretrizes a esse ensino nos anos iniciais e ensino fundamental. Do ponto de vista da maioria dos especialistas do campo das questões curriculares se tinha uma reflexão de que o reconhecimento desse ensino como componente curricular seria um artefato de legitimação e de reprodução do proselitismo e confessionalidade nas escolas. Já do ponto de vista da área das Ciências das Religiões o seu reconhecimento era um grande ganho para o campo das discussões que envolvem Educação e Religião na perspectiva da pluralidade religiosa, não religiosa como também as espiritualidades para a promoção da cultura de paz nas escolas.

Contudo, essa exclusão foi inesperada para muitos intelectuais e entidades que discutem esse documento, inclusive os defensores da inclusão do Ensino Religioso na BNCC, sendo assim, nos dias atuais as discussões acerca desse Ensinoestão se potencializando e instigando a levantar indagações tais como: O porquê do Ensino Religioso ter sido retirado da terceira e última versão da BNCC? Quais são os discursos produzidos nas Políticas Públicas educacionais para tal exclusão e novamente inclusão desse ensino na BNCC? Quais implicações e controvérsias acerca do nãoreconhecimento e ao mesmo tempo do reconhecimento do ER como componente curricular na BNCC?

É nesse sentido, que esse estudo se fortalece em uma perspectiva atual e original trazendo interlocuções entre as questões curriculares e a área da(s) Ciência(s) da(s) Religião(ões) apresentando avanços nas reflexões acerca da problemática que envolve o Ensino Religioso e o currículo. Para tanto, o presente estudo faz as seguintes abordagens: primeiramente iniciaremos com as discussões acerca das políticas de currículos educacionais. Em seguida faremos análise do discurso dessas políticas educacionais a respeito da exclusão do Ensino Religioso na Base Nacional Comum Curricular, bem como uma reflexão diante do retorno desse ensino no referido documento. Fazendo uma interlocução com as perspectivas sobre o discurso em Michel Foucault, dessa análise, que nos direcionam a levantar sinalizações e apontamentos que contribuem para a reflexão crítica dos sentidos e dos significados que a exclusão e a inserção do Ensino Religioso traz para as políticas curriculares educacionais.

\section{Estado - Currículo - Ensino Religioso}

No meio educacional ainda é muito presente o discurso do Ensino Religioso como doutrinação de uma de- 
terminada religião, legitimando de forma unânime o cristianismo como um conhecimento único a ser ensinado nas escolas, persistindo assim, o confessionalismo e o proselitismo nas práticas pedagógicas. Essa concepção no campo educacional se faz presente devido à construção simbólica e à relação de poder e de controle que as igrejas cristãs exercemdiretamente e/ou indiretamente sobre o Estado que se diz, teoricamente, ser laico. Ressaltamos que não é nossa pretensão e nem é o nosso foco nesse estudo aprofundar o debate acerca da laicidade, porém entendemos a importância de apresentar brevemente aqui a concepção política frente a um Estado laico, sendo assim, conforme Cury (2004, p. 183).

O Estado se tornou laico, vale dizer tornou-se equidistante dos cultos religiosos sem assumir um deles como religião oficial. A laicidade, ao condizer com a liberdade de expressão, de consciência e de culto, não pode conviver com um Estado portador de uma confissão. Por outro lado, o Estado laico não adota a religião da irreligião ou da anti-religiosidade. Ao respeitar todos os cultos e não adotar nenhum, o Estado libera as igrejas de um controle no que toca à especificidade do religioso e se libera do controle religioso. Isso quer dizer, ao mesmo tempo, o deslocamento do religioso do estatal para o privado e a assunção da laicidade como um conceito referido ao poder de Estado.

Diante de tal afirmativa, podemos dizer que o Brasil ainda não é totalmente laico e a religião permeia de forma indireta e/ou direta a esfera pública. Frente a essa discussão nos direcionamos nosso olhar para os símbolos religiosos em espaços públicos dando alguns exemplos como: o cristo redentor no Rio de Janeiro/RJ, crucifixos em tribunais, parlamentos, entre outros. E na esfera educacional temos o Ensino Religioso que se torna um campo de negociação frente a essa dicotomia, de um lado uma educação religiosa e de outro uma educação na perspectiva da laicidade.E essa dicotomia percorre em todos os seguimentos e discursos educacionais, principalmente, no campo do currículo quando nos deparamos com a presença, posteriormente a retirada e novamente a inclusão do Ensino Religioso na Base Nacional Comum Curricular, mas antes de adentrarmos profundamente sobre esse documento, precisamos compreender as tendências e posições teóricas e metodológicas do Ensino Religioso no tocante das políticas educacionais frente à diversidade de culturas que habitam nas escolas, e que cada vez mais estão se intensificando as discussões nas políticas de currículo por uma educação que reconheceas diferenças e as identidades culturais, de acordo com Moreira e Silva (1997, p. 28), "o currículo é um terreno de produção e de política cultural, no qual os materiais existentes funcionam como matéria prima de criação e recriação e, sobretudo, de contestação e transgressão".

Nessa conjuntura, temos as discussões da(s) Ciência(as) da(s) Religião(ões)/CR que militampelo reconhecimento do Ensino Religioso enquanto componente curricular mais expressivo que busca um ensino pluralista, transdisciplinar e intercultural. Compreendendo que nas dimensões religiosas, não religiosas e nas espiritualidades as culturas exercem um papel importante no reconhecimento de serem particulares e por terem identidades híbridas, assim, o respeito a essas dimensões precisa ser praticado e efetivado no planejamento analítico e sistêmico das políticas educacionais direcionadas ao Ensino Religioso. 
Tendo em vista que pensar no Ensino Religioso preocupado com a pluralidade cultural em uma perspectiva intercultural é um ato político, uma vez que no contexto social que estamos inseridos onde culturas negociam sua existência no embate entre dominação e resistência esse ensino fica vulnerável diante dessa dualidade. Essa é uma das grandes problemáticas acerca desse ensino, pedagogicamente falando, pois quando se trata de representações religiosas não pode haver preferencias e, tão pouco, ver uma religião assimetricamente das demais. Essas perspectivas precisam ser repensadas na dimensão política e cultural diante de um cenário que historicamente determinados grupos sociais, bem como suas crenças religiosas foram vitimas de práticas repressoras e cruelmente silenciadas, nas quais obrigatoriamente tiveram que negar sua identidade e seu reconhecimento social, com determinados grupos étnicos, principalmente, as religiões indígenas e afro-brasileiras.

E no âmbito educacional essas religiões sofreram e ainda sofrem preconceito e discriminação, utilizando o Ensino religioso como instrumento propício de reprodução dessas práticas. No entanto, defendemos aqui esse ensino na perspectiva da(s) CR, partindo de temáticas alusivas às práticas religiosas, não religiosas e as espiritualidades ancorando-se em metodologias que favoreçam a superação de violências de fins religiosos, promovendo a cultura de paz e o respeito à diversidade cultural fomentando, assim, possibilidades múltiplas de conhecimentos, interação dialógica e aprendizado entre todos os sujeitos que fazem parte do contexto escolar, em um trabalho envolvendo a tríade coletivista entre, escola - família - comunidade, não se limitando apenas entre a relação: educador e educando.
Mas como lidar com as diferenças religiosas nos currículos destinados ao Ensino Religioso onde se há um controle do Estado? Com essa questão, entendemos que no currículo escolar pouco se tem discutido e problematizado diante do Ensino Religioso com o olhar e a consciência de um ensino pluralista, em que sujeitos possam dialogar e interagir de forma aberta, dinâmica e humana com outros sujeitos, reconhecendo e respeitando a si e ao outro como diferente diante de suas crenças de cunho religioso, de não religioso, como também de espiritualidades que precisam ser consideradas em um mundo diverso culturalmente ao qual fazemos parte. Conforme Santos e Lacerda (2016, p. 300) reforçando que essa interação:

[...] é importante para compreendermos, reconhecer e respeitar as representações culturais do nosso contexto educacional, e o/a educando/a enquanto pessoa pensante e atuante a partir de um meio que não reconhece o diverso possa transformar criticamente essa realidade vivenciada, que é excludente e discriminatória as diversidades culturais religiosas consideradas minoritárias.

Nesse sentido, novas condições se evidenciam para o Ensino Religioso e emerge a necessidade de novas formas de pensar e organizar o currículo para agir nesse ensino, pois no contexto atual não cabe mais relacionar o Ensino Religioso como uma educação religiosa, como também, não podemos silenciar diante de atos prosélitos e confessionais nas práticas pedagógicas. É possível tecer que precisamos proporcionar um currículo a esse ensino com caráter político e cultural e de tendências e posições teórico e metodológico como cultura dialógica e interativa que proporcione os sujeitos observarem suas próprias ações nas suas vidas diárias e, 
principalmente na relação de coletividade, onde as identidades e subjetividades são percebidas e consideradas.

Advogando aqui a importância do rompimento efetivo do controle social da igreja sobre o Estado que exerce seu poder nos currículos escolares nos quais utilizam as políticas de currículo no Ensino Religioso, como dito anteriormente, como campos de negociações, de reproduções das relações de poder nas práticas metodológicas e curriculares para esse ensino. Essa afirmativa se fortalece diante das constantes reformulações curriculares, e, recentemente nos deparamos com uma dessas reformulações, o caso, da inserção e retirada do Ensino Religioso na Base Nacional Comum Curricular - BNCC.

\section{Base Nacional Comum Curricular: Avanços e retrocessos no Ensino Religioso}

Diante dos contrapontos, aqui já apresentados e discutidos, das políticas de currículos no Ensino Religioso, nas quais entre essas políticas, temos a Base Nacional Comum Curricular BNCC. Esta, por sua vez acarreta por trás do discurso político educacional de melhoria na educação, uma lógica mercantilista e capitalista, que atende cobiças empresariais privadas. A respeito desta ideia de um currículo comum nos aproximamos da ótica da Süssekind (2014) quando ela se remete as discussões de currículo como uma conversa complicada através da perspectiva de William Pinar, conforme a autora:

Trago para esta conversa complicada alguns recortes de encontros, debates e publicações recentes na mídia que trazem ao palco de disputas diversas noções de currículos. Representando diferentes grupos e interesses sociais, às vezes de modo pouco declarado, estão no debate MEC, Instituto Nacional de Estudos e Pesquisas Educacionais Anísio Teixeira (Inep), União Nacional dos Dirigentes Municipais de Educação (Undime), aqueles que se apresentam como "o grupo ue defende a BCN" , entidades de classe, associações da sociedade civil e de professores, empresários da educação, empresários do mercado editorial, institutos e fundações, entre outros interessados. (SÜSSEKIND, 2014, p. 1517)

Diante de tal enunciação, podemos afirmar a nossa visão contrária a BNCC, uma vez que a logística da Base é compartilhar conhecimentos e objetivos comuns a todos, mas que conhecimentos e objetivos de ensino queremos que sejam trabalhados nas escolas? Será que esses conhecimentos e objetivos são viáveis em uma Base Nacional Comum para todos? Todos terão o mesmo acesso aos conhecimentos e objetivos de ensino? Essas são apenas algumas inquietações que precisam ser questionadas quando pensamos na BNCC. E, é nesses questionamentos que percebemos a importância de pensarmos nas criticas contrárias da maioria dos currilistas acerca da implementação e execução da BNCC.

Contudo, nesse novo cenário atual que estamos enfrentando no campo do currículo nos deparamos com mais uma fragilidade da Base Nacional Comum Curricular, com a retirada do Ensino Religioso em sua última versão. Embora, havendo a preocupação em se ter um currículo único escolar diante da singularidade de cada contexto social que é multicultural e de específicas identidades, essas questões, quando nos direcionamos ao Ensino Religioso percebemos uma complexidade quando limitamos a um único currículo comum a todos. Além disso, "As identidades são 
construídas por meio das diferenças e não fora delas" (HALL, 2009, p. 110). É nesse sentido, que permeiam as discussões curriculares onde as identidades e as subjetividades devem ser consideradas no currículo, principalmente, no currículo escolar. Uma vez que, de acordo com Silva (2007, P. 117) "o currículo como representação", assim, o discurso exerce um grande poder social, sendo que por meio deste "constrói-se "identidades", cria-se "representações"'(SILVA 2017, p. 117). Com essa compreensão, queremos aqui fazer uma análise dos sentidos e impactos que podem causar diante da manutenção do ER na BNCC e algumas considerações que são evidenciadas diante a exclusão desse ensino na última versão do referido documento. No estudo comparativo entre a segunda versão reformulada e a terceira versão da BNCC disponibilizado pelo MEC, podemos observar que esse órgão federal faz a seguinte justificativa para a retirada do Ensino Religioso no Ensino Fundamental - Áreas do Conhecimento e Componentes Curriculares.

A área de conhecimento de Ensino Religioso e o respectivo componente curricular, presentes na Versão 2 da BNCC, foram excluídos da Versão Final em atenção ao disposto na LDB: a Lei determina que o Ensino Religioso seja oferecido aos alunos do Ensino Fundamental nas escolas públicas em caráter optativo, cabendo aos sistemas de ensino a sua regulamentação e definição de conteúdos (Art. 33, $\S 1^{\circ}$ ). Portanto, sendo esse tratamento de competência dos Estados e Municípios, aos quais estão ligadas as escolas públicas de Ensino Fundamental, não cabe à União estabelecer base comum para a área, sob pena de interferir indevidamente em assuntos da alçada de outras esferas de governo da federação.
- Na Versão 2 da BNCC, previam-se objetivos de aprendizagem para o componente curricular Língua Estrangeira Moderna. Na Versão Final, as habilidades a ser desenvolvidas pelos alunos no Ensino Fundamental - Anos Finais passam a se referir a uma língua estrangeira específica: a Língua Inglesa. A BNCC trata das aprendizagens essenciais a ser asseguradas a todos os alunos da educação básica - e, portanto, daquilo que é comum, obrigatório. Anteriormente, a LDB não trazia a Língua Inglesa como estudo obrigatório. Todavia, a Lei $n^{\circ} 13.415$, de 16 de fevereiro de 2017, altera a LDB: torna a Língua Inglesa obrigatória desde $06^{\circ}$ ano do Ensino Fundamental (Art. 26, $\S 5^{\circ}$ ) e define que, no Ensino Médio, os sistemas de ensino poderão, se assim desejarem, ofertar outras línguas estrangeiras em caráter optativo, preferencialmente a Língua Espanhola (Art. 35-A, § $4^{\circ}$ ). (MEC, 2017, P.12)

Como podemos observar o discurso produzido acima apenas remete a consonância com Lei de Diretrizes e Bases da Educação - LDB que dá a esse ensino caráter optativo, entretanto, no artigo 33 da LDB diz que a matrícula dos educandos nesse ensino que é optativa, uma vez que na Constituição Federal de 1988 o Ensino Religioso é uma disciplina que deve ser ofertada obrigatoriamente nas escolas públicas. Nesse sentido, a argumentação posta pelo MEC baseada apenas no quesito da disciplina ser optativa se torna fragilizada e/ou equivocada, já que há a oferta obrigatória. Diante de tal alegação, é necessário refletir a respeito das duas versões anteriores da BNCC como o MEC não se atentou a essas questões, de oferta obrigatória e de matrícula facultativa? Uma vez que desde a elaboração da primeira versão da BNCC esse órgão federal abriu es- 
paço para a população dar sugestões, no entanto, acatando assim, algumas reformulações que consideramos positivas na segunda versão. Conforme a segunda versão reformulada da BNCC, temos:

[...] tanto a Constituição Federal de 1988, quanto a Lei de Diretrizes e Bases da Educação Nacional (LDBEN) $n^{\circ}$ 9.394/1996, redefiniram os fundamentos epistemológicos e pedagógicos do Ensino Religioso, atendendo a reivindicações da sociedade civil, de sistemas de ensino e de instituições de Educação Superior que almejavam o reconhecimento de culturas, de tradições e de grupos religiosos e não religiosos que integram a complexa e diversa sociedade brasileira. (BNCC, 2016, p. 170)

Como podemos identificar na citação acima, o próprio documento na segunda versão reformulada faz menção, tanto a Constituição quanto a LDB, neste caso, fica clarividente que a BNCC foi elaborada ciente a respeito da oferta obrigatória e a matrícula facultativa do Ensino Religioso. Se há essa clareza, qual o motivo então, na sua terceira versão, o ER ter sido excluído? Nesse caso, o discurso estabelecido para argumentar a retirada desse ensino na BNCC se torna contraditório frente às comparações das duas versões. Quando nos referimos ao discurso recorremos a uma abordagem Foucaultiana. Assim, Foucault, no livro $A$ ordem do discurso (2007), conceitualiza o discurso onde é produzido em função das relações de poder e no livro Arqueologia do Saber (1986), o autor traz elementos sócio-históricos fundamentais para compreender a constituição da formação do discurso como prática em um contexto das relações sociais.

Para esse autor, "o discurso não é simplesmente aquilo que traduz as lutas ou os sistemas de dominação, mas aquilo por que, pelo que se luta, o poder do qual nós queremos apoderar" (FOUCAULT, 2007, p.10) entendemos que o discurso comumenterelaciona-se com o poder. Nesse sentido, o discurso é um mecanismo de hierarquizar conhecimentos e legitimação de poder, assim, percebemos que por trás da linha de argumentação frágil justificando a exclusão do Ensino Religioso há categorias de interesses que hierarquizam, excluem e reproduzem campos de disputas onde as relações de poder são legitimadas no âmbito político educacional.

Continuando com o autor "o discurso está intimamente ligada à questão da constituição do sujeito social. [...] os sujeitos sociais não são causas, não são origem do discurso, mas são efeitos discursivos". (FOUCAULT, 1986, p.109). Nessa perspectiva, a argumentação da retirada do ensino religioso se torna um discurso camuflado de imposição do que se quer formar o sujeito social diante de uma Base Nacional Comum Curricular que estabelece um currículo comum, trazendo conhecimentos e objetivos de ensino que estabelecem hierarquias sociais, econômicos e etnias, etc. Retirando assim, os conhecimentos que podem por sua vez, refletir criticamente as linhas traçadas de hegemonias e reproduções de poder. Nesse tocante, o Ensino Religioso como previsto na segunda versão reformulada da BNCC não atendia a essa logística, sendo assim, a sua não contemplação na última versão desse documento.

Consideramos plausíveis algumas reformulações feitas na segunda versão da BNCC devido à proposta que defendemos no Ensino Religioso enquanto conhecimento rizomático em uma ótica pluralista e de respeito à diversidade cultural, no que tange as questões religiosas, não religiosas e as espiritualidades, e percebemos que na segunda versão 
revista da Base estava se direcionando para esse trajeto. Esse reconhecimento vai além da simplificação de uma ideia de comum, no qual se tem um Ensino Religioso que percebe nuances diante das questões que envolvem o campo das religiões. Verificamos isso na citação abaixo que é um recorte da segunda versão reformulada da BNCC no qual o Ensino Religioso estava posto com maior visibilidade no que diz respeito da necessidade de um diálogo intercultural e inter-religioso nesse componente curricular. Como podemos observar:

\begin{abstract}
A área do Ensino Religioso não se reduz à apreensão abstrata dos conhecimentos religiosos, mas se constitui em espaço de vivências e experiências, intercâmbios e diálogos permanentes, que visam ao enriquecimento das identidades culturais, religiosas e não religiosas. Isso não significa a fusão das diferenças, mas um constante exercício de convivência e de mútuo reconhecimento das raízes culturais do outro/a e de si mesmo, de modo a valorar identidades, alteridades, experiências e cosmovisões, em perspectivas interculturais. (BNCC, 2016, p.170)
\end{abstract}

Com essa visão, o ER que estava proposto trazia uma abordagem pedagógica pensando na formação do ser enquanto pessoa que reconhece o outro com suas diferenças, crenças e/ ou não crenças de cunho religioso e de espiritualidades, no qual o respeito é tema central nesse processo de ensino e aprendizagem quando pensamos em conhecimentos e objetivos direcionados ao Ensino Religioso que possibilite a reflexão crítica dos educandos provocando, assim, uma discussão que leve os sujeitos da escola a compreender os processos de exclusão e desigualdades, no sentido de buscar estratégias pedagógicas e metodológicas nas práticas educativas a serem trabalhadas para o combate a todas as configurações de hegemonização diante das questões que envolvem esse ensino, possibilitando a contemplação das religiões, das espiritualidades, entre outras questões religiosas e não religiosas, que existem no contexto das relações sociais em que estamos inseridos, proporcionando, assim, um ensino para a reflexão, conscientização e transformação de uma sociedade preconceituosa e intolerante com as demais religiões que foram e ainda são vítimas de preconceito devido à legitimação, ao longo da história, das religiões consideradas cristãs.

Frente a essa discussão, o Ensino Religioso se ressignifica ganhando visibilidade e assumindo um papel preponderante em uma proposta pluralista, crítica, e de respeito à diversidade cultural, contudo essa perspectiva de ensino se torna uma problemática e até mesmo uma "ameaça" diante da atual conjuntura política que estamos vivenciando, onde temos representações no Congresso Nacional em que na sua maioria são declaradamente da religião cristã, principalmente evangélica e, essa é mais uma questão a ser analisada, pois a relação entre a cultura, o conhecimento e o poder se manifesta quando as representações políticas decidem que conhecimentos, que culturas são consideradas como "verdadeiras" a serem abordados e desempenhados no papel de escolarização. Essas são principais quesitos abordados por Michel Apple em seu livro "Educando à direita: mercados, padrões, Deus e desigualdade" (2003). Apple faz uma análise crítica e posiciona-se contra as reestruturas e reformas radicais conservadoras no campo educacional, assim, o autor conceitualiza precisamente esse determinado seguimento representativo como "populistas autoritários - fundamentalistas religiosos e evangélicos conservadores que querem um re- 
torno a (seu) Deus em todas as nossas instituições". (APPLE, 2003, p. 13)

Diante dessa concepção, os populistas autoritários com posicionamentos conservadores visam um Estado regido pelos fundamentos cristãos, e, isso implica na legitimação dos conhecimentos influenciando e/ou impondo no que pode e no que não pode ser ensinado nas escolas, pois a escola é percebida enquanto um campo de disputa da igreja produzindo currículos cujas correntes são dogmáticas e conservadoras daquilo que consideram como conhecimento "legítimo", nesse sentido, o discurso produzido por esses determinados grupos acerca do conhecimento é camuflado na ideia de neutralidade e imposto nas escolas (APPLE, 2003). E, um exemplo desse discurso, é a elaboração do projeto de lei "Escola sem partido”. Conforme Frigotto (2017, p. 09):

O Escola sem Partido utiliza-se de uma "linguagem próxima do senso comum, recorrendo a dicotomias simplistas que reduzem questões complexas a falsas alternativas", e expande-se por meio de memes, "imagens acompanhadas de breves dizeres", por "quatro elementos principais: primeiro, uma concepção de escolarização; segundo, uma desqualificação do professor; terceiro, estratégias discursivas fascistas; e, por último, a defesa do poder total dos pais sobre os seus filhos". Contém estratégias discursivas fascistas através de "analogias voltadas à docência, que desumanizam o professor", tratando-o como "um monstro, um parasita, um vampiro" na forma de memes ofensivos, incluindo Gramsci e Paulo Freire. Instalam um "clima de denuncismo" e "um discurso de ódio".

De acordo com o autor, podemos identificar que esse projeto de lei é uma forma de controlar o que pode ser ensinado e aprendido nas escolas, em que práticas discriminatórias, excludentes, preconceituosas e doutrinárias são camufladas em um discurso de neutralidade, nesse projeto de lei o conhecimento escolar é direcionado para uma visão ideológica de conservadorismo neoliberal. E referindo ao Ensino Religioso no documento "Escola sem partido" aponta para o retorno do ensino moral e cívico subvertendo quaisquer reflexões críticas acerca da diversidade cultural religiosa, não religiosa como também as espiritualidades. Por que abordar o projeto de lei "Escola sem Partido" nesse estudo? Para poder entender como esses grupos denominados conforme Apple (2003) de populistas autoritários estão se organizando e crescendo no campo da política brasileira, em que esses grupos estão elaborando, estruturando e deliberando políticas públicas voltadas para educação, retrocedendo assim, nosso ensino ditando e estabelecendo uma escola que, na verdade, pressupõe de um único partido, de um único conhecimento, de uma única cultura e de uma única religião.

O foco desse estudo não é aprofundar as discussões a respeito da Escola sem Partido, entretanto, quando nos remetemos a BNCC, logo, não podemos desconsiderá-lo, pois tanto a BNCC, a Escola sem Partido como também a Reforma do Ensino Médio estão diretamente ligados, e, são documentos governamentais que retrocedem e prejudicam a nossa educação. Assim, é notório identificar que uma educação democrática proposta no ER e contemplada na segunda versão reformulada da Base não poderia ser viável, diante de um era conservadora que estamos vivenciando, a partir da nossa análise Ensino Religioso foi retirado de forma estratégica na terceira versão da Base Nacional Comum Curricular, no entan- 
to, recentemente, temos a inclusão novamente desse ensino na BNCC. Com essa nova inclusão, (re)surgem preocupações acerca desse componente curricular, como o ER contemplará em um currículo único as tradições culturais, uma vez que essas tradições se apresentam com manifestações culturais religiosas diferentes que variam de acordo com determinadas regiões? E de que forma o ER irá separar as convicções religiosas dos conteúdos a serem abordados em um currículo pré-estabelecido? É considerável fazer essas indagações por estarmos diante de concepções doutrinárias previstas por esses determinados grupos autoritários que ganham cada vez mais força no nosso cenário político,retornando assim, o conservadorismono campo educacional brasileiro.

\section{Conclusão}

Diante do que foi exposto nesse estudo, é possível perceber que as discussões apontadas aqui são algumas de muitas inquietações quando pensamos no Ensino Religioso e sua visibilidade no campo das políticas de currículo direcionado para educação, nesse sentido, não temos a pretensão de nos limitarmos as discussões propostas aqui nesse estudo. Contudo, fizemos algumas sinalizações que podem possibilitar outras reflexões para potencializar teoricamente, esptemologicamente e pedagogicamente as novas tendências que nos fazem defender o Ensino Religioso nas escolas públicas. Levantando assim, novas possibilidades para os estudos curriculares frente a um ensino que possa contribuir de forma significativa no combate de quaisquer formas de proselitismo e confessionalismo no processo de ensino e aprendizagem.

No entanto, apesar de termos elencado pontos negativos com a im- plementação da Base Nacional Comum Curricular nas escolas brasileiras, defendemos aqui a importância da inserção do Ensino Religioso na BNCC, devido à perspectiva de pluralidade, de respeito das diversas culturas e de abertura de novos caminhos para a cultura de paz nas escolas. Para o terreno da(s) Ciências(as) da(as) Religião(ões) o reconhecimento do ER enquanto componente curricular como previsto nas versões anteriores, é um grande marco e avanço na militância desse ensino no combate a intolerância religiosa, uma vez posta na Base, necessitaria de formação (inicial e continuada) adequada, no caso, uma formação no(s) curso(s) de CR de educadores para poder lecionar esse componente curricular.

Diante da nossa análise, a ideia de que a BNCC garante as mesmas oportunidades para todos como previsto no documento se contradiz a partir do momento que o ER foi excluído na sua última versão, e, essa exclusão nos permite concluir, portanto, que o documento proposto é mais um artefato que legitima hegemonias, preconceitos, discriminações, e relações de poder no que se refere às questões religiosas. Dando ainda maior visibilidade as religiões consideradas cristãs e desconsiderando de forma direta e/ou indireta as demais religiões, e, as outras formas de crenças/ não crenças, como também as espiritualidades em um processo de negação de si e do outro no âmbito educacional. Porém com a nova inserção do ER na BNCC, nos direcionamos para a necessidade e a importância da presença desse ensino nas escolas públicas para possibilitar um espaço de construção de novos conhecimentos por meio do currículo e das práticas curriculares que identificam e consideram as individualidades, as subjetividades e as identidades. 


\section{Bibliografia}

APPLE, Michael. Educando à direita: mercados, padrões, Deus e desigualdade. São Paulo: Cortez/Instituto Paulo Freire, 2003.

BRASIL. Base Nacional Comum Curricular: Estudo comparativo entre a versão 2 e a versão final. Ministério da Educação - MEC, 2017. Disponível em: <http://cnebncc.mec.gov.br/ docs/BNCC_Estudo_Comparativo.pdf $>$ Acesso em: Maio 2017.

CURY, Carlos Roberto Jamil. Ensino religioso na escola pública: o retorno de uma polêmica recorrente. Revista Brasileira de Educação. $\mathrm{N}^{\circ}$ 27, 2004. Disponível em: <http://www. scielo.br/pdf/rbedu/n27/n27a12.pdf $>$ Acesso em: Maio, 2017.

FOUCAULT, Michel. A ordem do discurso: aula inaugural no College de France, pronunciada em 2 de dezembro de 1970. 15a .ed. São Paulo: Loyola, 2007.

ro: Forense, 1986.

A Arqueologia do saber. Rio de Janei-

FRIGOTO, Gaudêncio (org). Escola "sem" partido: esfinge que ameaça a educação e a sociedade brasileira. Rio de Janeiro: UERJ, LPP, 2017.

HALL, Stuart. Quem precisa de identidade? In: SILVA, Tomaz Tadeu (Org.). Identidade e Diferença: a perspectiva dos Estudos Culturais. Petrópolis: Vozes, 2009.

MOREIRA, Antonio Flávio Barbosa; SILVA, Tomaz Tadeu. (Org.). Currículo, cultura e sociedade. 2. ed. São Paulo: Cortez, 1997.

SANTOS, Mirinalda Alves Rodrigues dos. LACERDA, Thalisson Pinto Trindade de. (Re) significando os sentidos de currículo e interculturalidade no ensino religioso: desafios no contexto da globalização. In: VIII Congresso Nacional do Ensino Religioso-CONERE, 2016, Recife/PE. Anais do Congresso Nacional de Ensino Religioso. Florianópolis/SC: FONAPER, 2016, p. 290-304.

SILVA, Tomaz Tadeu da. O currículo como fetiche - A poética e a política do texto. Autêntica, 2007.

SÜSSEKIND, Maria Luiza. As (im)possibilida- des de uma Base Comum Nacional. Revista e-Curriculum, São Paulo, v. 12, n. 03 p.15121529, out./dez. 2014. Disponível em: <https:// revistas. pucsp.br//index. php/curriculum $>$.Acesso em: Maio, 2017.

\section{Recebido em 26/07/2017 Aprovado em 14/09/2017}

I Doutoranda e Mestra pelo Programa de Pós-Graduação em Ciências das Religiões pela Universidade Federal da Paraíba - PPGCR/UFPB, na linha de pesquisa Educação e Religião. Graduada em Pedagogia pela mesma instituição. Email: mirirodrigues2@gmail.com 